\title{
RECONCEPTUALISING CREM ALIGNMENT TO ACCOUNT FOR WASTE
}

\author{
Tuuli Jylhä ${ }^{1}$
}

\begin{abstract}
Every business needs a place to operate. The management of corporate operational assets is called Corporate Real Estate Management (CREM). In the era of sustainability, smart use of real estate as the second-largest asset of corporations is needed. The purpose of the paper is to reconceptualise CREM alignment to feature the waste concept in smart use of CRE resources. This research is limited to the conceptual analysis of CREM alignment.

The reasoning is based on integrative literature review. In general management theories, alignment is divided between vertical and horizontal alignments within and across organisations. In CREM literature, vertical alignment within an organisation is dominant while horizontal alignment within an organisation and across organisations has gained minimal attention.

The conceptual analysis indicates that there is plenty of waste in CREM. Lean aligns especially horizontally and offers a way for smart alignment, i.e., a smart use of CRE resources including not only the use of materials and energy but also the use of human resources with their social capital.
\end{abstract}

\section{KEYWORDS}

Corporate real estate, corporate real estate management, alignment, waste, added value.

\section{INTRODUCTION}

Every business needs a place to operate. The real estate needs of a museum, stadium, law firm, health care centre, retail chain or a car manufacturing company are unique. The management of these operational assets to house corporate's business is called Corporate Real Estate Management (CREM) (Edwards and Ellison, 2004; CoreNet Global, 2016). In corporations, real estate is often undermanaged although it is the second-largest cost of companies after human resources (Edwards and Ellison, 2004).

In CREM, real estate is seen from the user perspective, not from the investor's or service provider's perspective. During the life-cycle of a building, the CRE manager represents the user in the design and construction phases, manages the use and reuse phases of the building and is the key respondent in the reuse, recycle and redistribution of the materials in the demolition phase of owned properties.

1 Assistant professor, Department of Management in the Built Environment, Delft University of Technology, Delft, The Netherlands, +31 62486 6609, t.e.jylha@tudelft.nl 
In the era of sustainability and smart use of resources, the smooth cooperation and value delivery during the entire building life-cycle is highlighted. To avoid excess use of resources is one of the main concepts in lean construction, but hardly known in the field of CREM. Instead, two other concepts have a dominant role in the current CREM literature: alignment and added value. Alignment is typically adapted from strategic management literature, as Heywood and Arkesteijn (2017) concluded, and the concept of added value after Porter. Both concepts are widely used and accepted in the CREM literature (e.g., Krumm et al., 2003; Jensen et al., 2012) and illustrated in the often used CREM definition:

CREM is "the alignment of the real estate portfolio of a corporation or a public authority to the needs of the core business, in order to obtain maximum added value for the business and to contribute optimally to the overall performance of the organisation" (Dewulf et al., 2000).

In this paper, it is argued that CREM theories benefit from the adaption of the waste concept. The purpose of the paper is to reconceptualise CREM alignment to feature the waste concept in smart use of CRE resources. Waste in this paper is defined after Bølviken et al. (2014): "the use of more than needed and unwanted output".

To reconceptualise, the reasoning is based on integrative literature review as proposed by Torraco (2005). First a summary of alignment theories from strategic and operational management literature is presented and then CREM alignment literature is analysed with an integrative approach.

\section{ALIGNMENT}

In this section, the alignment types inside an organisation (organisational alignment) and across various organisations (cross-organisational alignment) are briefly presented.

\section{ORGANISATIONAL ALIGNMENT}

Alignment is studied in many disciplines and, consequently, the literature has matured but also siloed. The used terminology varies from field to field and other terms, such as fit, integration, harmony, coherence and linkage, are often used. In this paper, the term 'alignment' is used due to its common acceptance and use in the CREM literature.

This paper follows a model of Kathuria et al. (2007) on the hierarchy of alignment within an organisation. In the model, alignment is divided into vertical and horizontal alignment (Figure 1): vertical alignment goes through the entire organisation and horizontal alignment on two levels: functional and intra-functional. Next, the three main organisational alignment types are briefly presented.

(1) Vertical alignment, also called hierarchal alignment, refers to the consensus of "strategies, objectives, action plans and decisions throughout various levels of the organisation" (Kathuria et al. 2007). Vertical alignment is a commonly used concept between three levels - corporate, business and functional levels (1a-1b in Figure 1). In their model, Kathuria et al. (2007) presented that vertical alignment depends also on the fourth level: on the decision areas within a function (1c in Figure 1).

Horizontal alignment is explained through two forms of alignment (Kathuria et al., 2007): (2) cross-functional and (3) intra-functional alignment. Cross-functional alignment 
refers to the fit between different corporate functions ( 2 in Figure 1), such as HR, ICT, marketing, operations and real estate (RE). Intra-functional alignment refers to the fit between different decision areas and their actions within each function ( 3 in Figure 1). Kathuria et al. (2007) highlighted that intra-functional alignment requires also vertical alignment: the decisions and actions between decision areas are aligned with the policy documents of that function and these have a fit with the overall corporate strategy.

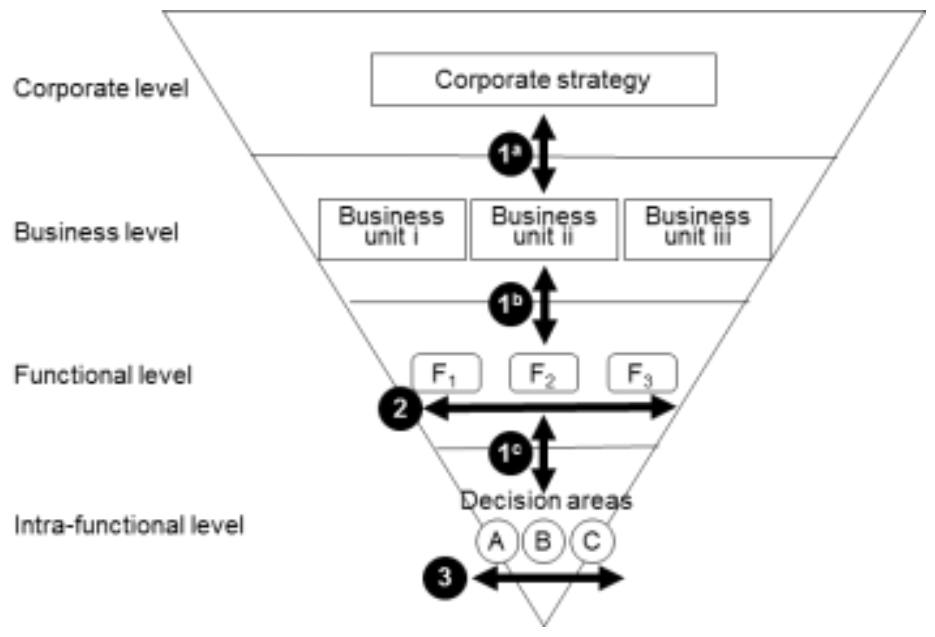

Figure 1: Summary of organisational alignment (adapted from Kathuria et al. 2017)

\section{Vertical (strategic) alignment}

Traditionally, strategy design is seen as an iterative, top-down process, where the strategy design on corporate levels leads the iteration. However, a bottom-up approach is also discussed in the literature (Kathuria et al., 2007). The early pioneer presenting the bottomup approach was Skinner (1974), who encouraged to see manufacturing as a strategic weapon for corporations instead of as simply conforming to the corporate strategy without two-way dialogue. Hayes and Pisano (1994) stated that corporations often "focus on the form of their asset", such the type of technology the corporation has, "rather than on their substance" such as skills and capabilities to use that technology. Wheelwright and Hayes (1985) were in line with Skinner and identified four stages in how manufacturing contributes to the strategic objectives of an organisation:

STAGE 1: By minimising the negative potential of manufacturing (internally neutral)

STAGE 2: By following industry practice to achieve parity with competitor (externally neutral)

STAGE 3: By providing internal support for the business strategy (internally supportive)

STAGE 4: By providing competitive advantage (externally supportive)

\section{Cross-functional and intra-functional alignment}

Cross-functional and intra-functional alignments as horizontal alignment types have been studied less than vertical alignment and, thus, the related research is sparse (Kathuria et al. 
2007). Two of the early pioneers are Henderson and Venkatraman (1989; 1993), who proposed that in addition to strategic integration, operational integration is also needed. By operational integration they referred to horizontal alignment inside an organisation.

There are few fields where horizontal alignment is studied more. One of these fields is operations management, where terms such as 'process re-engineering', 'process redesign' and 'process improvement' (Lee and Dale, 1998) are used instead of alignment. In operations management, alignment refers to "arrangements of various parts in a company so that they work together harmoniously" (Yuan Hung et al. 2010). To work together means that organisation is not solely moving to the same direction but is also capable of minimising its internal inefficiencies (Alagaraja et al. 2015). This leads to an idea of increased value and removed rework and other types of waste when the process is streamlined (Benner and Tushman, 2003). This requires functional understanding of processes including "individual, functional, cross-functional and cross-organizational processes" (Alagaraja et al. 2015).

\section{Cross-Organisational ALIGNMENT}

By continuing the idea of the previous chapter, horizontal alignment is also needed in crossorganisational processes (Alagaraja et al., 2015). For example, supply chain management (SCM) or value chain management (VCM) represent this type of cross-organisational alignment. According to Vrijhoef and Koskela (2000) and Schniederjans et al. (2010), the early traces of SCM can be traced back to JIT delivery systems in Toyota Production System (TPS) and to the quality control field pioneered by Shewhart, Deming, and Juran. Cooper and Ellram (1993) highlighted that SCM focuses on "the total flow of a distribution channel from the supplier to the ultimate user" instead of focusing on few players in that supply chain.

According to Schniederjans et al. (2010), waste and inferior results can be avoided by aligning strategies, tactics and operational plans. They continued that lean aligns especially horizontally within an organisation and across organisations. Lean contributes by improving effectiveness and efficiency of the supply chain operations. Effectiveness refers to the value proposition (i.e. doing right things) and efficiency to waste elimination (i.e. doing things right).

\section{CREM ALIGNMENT}

Next, organisational and cross-organisational alignments are presented from the CREM perspective.

\section{Organisational CREM AlignMent}

\section{Vertical (strategic) CREM alignment}

Vertical alignment means that CRE unit is strategically aligned with the overall strategy or/and business units' strategies. In CREM literature, this strategic alignment has gained a lot of attention (e.g., Weatherhead 1997; Nourse and Roulac, 1993; Lindholm 2006). The RE strategy design process covers both approaches - top-down and bottom-up - but, according to Heywood and Arkesteijn (2017), the top-down approach is more dominant. 
Similarly, the alignment between the business level (Figure 1) and the RE function on the functional level (Figure 1, level 3) is highlighted for example by Appel-Meulenbroek et al. (2010), Then and Tan (2013) and Then et al. (2014).

In CREM literature, the golden idea is that CRE can contribute to the strategic objectives of an organisation, similarly as Wheelwright and Hayes (1985) proposed it in their four stage model. In the last 20 years, CREM literature has strongly emphasised the added value perspective: CREM literature often presents the idea that CRE is no longer seen as a cost or necessary burden for corporations, but that CRE can support corporation's business objectives and add value (e.g., in Nourse and Roulac, 1993; Lindholm 2006; Appel-Meulenbroek et al., 2010). According to Van der Voordt (2017), the added value discussion in the CREM field was initiated by Hans de Jonge in his EuroFM presentation in late 1990's. After this, a strong body of knowledge has been established for example to present (e.g., Krumm et al., 1998; Lindholm and Leväinen, 2006) and to measure (e.g., Lindholm and Nenonen, 2006; Riratanaphong, 2014; Jensen and Van der Voordt, 2017) the added value of CREM.

Despite the common idea of contributing to the overall business strategy, the four-stage model of Wheelwright and Hayes (1985) is not directly used in the mainstream CREM literature. CREM alignment literature has two streams (Jylhä et al. 2019). In the first stream, the role of added value of RE is highlighted in the overall contribution to the business: RE can add value for example by promoting human resources objectives (Roulac 2001); by increasing employee satisfaction and productivity (Lindholm, 2008; Jensen, 2008; Den Heijer, 2011); by increasing and capturing the value of corporate assets (Roulac 2001; Lindholm, 2008); and by promoting marketing and sales of the corporation (Lindholm, 2008; De Jonge 1996). In the second stream, CRE is seen to contribute to the overall business by strengthening the competitive advantage of the corporation (Jylhä et al., 2019). Compared to the four-stage model of Wheelwright and Hayes (1985), these streams remind the supportive stages 3 and 4, respectively. Interestingly, stage 2 (to minimise the negative potential of CRE and to achieve parity with competitor) has received less attention.

\section{Cross-functional and intra-functional CREM alignment}

From CREM perspective, cross-functional alignment means that the performance and actions of the CRE function fit with the performance and actions of other functions on the corporation's operational level, such as HR, ICT, marketing and operations. In the literature, the importance to achieve this fit is often acknowledged (e.g., Lindholm et al., 2006; Harris and Cooke 2014), but the literature still lacks research that would further study this type of alignment (Jylhä et al 2019).

Intra-functional CREM alignment aims to find a fit between the decision areas of the CREM function. When following the model of Dewulf et al. (2000), these decision areas are called facility management, cost control and asset management. These same decision areas are found in other models. For example, Leväinen (2013) calls these, respectively, facility and workplace management, property management and asset management. Despite how the decision areas are called, there are only few remarks related to intra-functional alignment between the decision areas. One of those is the integrated resource management framework by then (2005). In his model, he highlights the two-way integration of the 
different decision areas. Similarly, the intra-functional alignment is touched in the model of Dewulf et al. (2000) by illustrating CREM as a linking pin between the decision areas. However, the model does not further explain how this is done.

The vertical alignment within CREM functions has been highlighted more. In many models, such as in those of Nourse and Roulac (1993), Weatherhead (1997) and then (2005), the CRE strategy gives a direction for all the decision areas to follow. There are also models for designing a RE strategy in line with the corporate strategy (e.g., Edwards and Ellison, 2004; De Jonge et al., 2009).

To summarise, in the CREM literature cross-functional and intra-functional alignments are studied less than vertical (or strategic) alignment, similarly as in the general alignment literature.

\section{Cross-organisational CREM alignment}

The supply chains of CRE functions are manifold. CREM literature has shown that a great deal of CREM functions are outsourced, i.e., activities and tasks are done across organisations and the product and service delivery is allocated along several supply chains. For example, Sharp (2013) and McCarty and Gottschalk (2014) stated that it has been a trend to outsource especially strategically non-important activities. The spectrum of these services is wide and it also varies between organisations. For example, in the model of Heywood and Kenley (2013), procurement covers technical and user services, management services, and construction and property development services. In addition, the limited inhouse capacity might require to acquire some of the CRE management tasks from an external service provider (Heywood and Kenley, 2010; 2013). This means that an external service provider, who delivers CREM services, acts on behalf of the CRE function based on the agency commitment. Heywood and Kenley $(2010,2013)$ named this 'the extended CRE organisation'.

Due to the heavy outsourcing and related structures, horizontal CREM alignment across organisations is needed. Unfortunately, CREM literature includes limited amount of research focusing on aligning its horizontal supply chain across organisations. It seems that horizontal alignment is more or less left at the responsibility of the other decision areas, such as facility management and maintenance management. For example, in facility management, supply chains are often discussed but the discussion is centred around sourcing strategies and related contractual responsibilities (e.g., Jensen and Van der Voordt 2017; Lehtonen and Salonen, 2006). In recent years, the focus in FM has been on the added value on strategic level (e.g., Then et al. 2014; Jensen et al. 2012), similarly as in the field of CREM, and operational excellence has gained less attention. One of the few exceptions is Jylhä (2013), who studied a selection of real estate service processes. She concluded that the separate sub-processes interrupt the value creation and that a comprehensive management of the value chain is missing.

\section{CONCLUSIONS}

Based on the conceptual analysis, the potential of waste is not yet acknowledged in the field of CREM. This paper claims that there is plenty of waste intertwined in CREM. In fact, the current CREM alignment theories have created a good environment for waste. 
One explanation is the transformation view used to conceptualise the value delivery. A value delivery that is based on sub-processes with many players is a good condition for waste. In CREM, even the management responsibility of the value delivery is typically divided in the extended CRE organisation between the inner stakeholder and external agent. Another explanation that provides a good condition for waste is the heavy focus on one specific aspect of alignment, namely on strategic alignment. The CREM field is not alone with this feature. For example, recently Trevor and Varcoe (2017) stated that

"The challenge is that executives tend to focus on one of these areas [strategies, organizational capabilities, resources, and management systems] to the exclusion of the others, but what really matters for performance is how they all fit together."

The applicability of waste in reconceptualising CREM alignment is manifold. First, being able to reduce waste in functional alignment ( 2 in Figure 1 ) means that RE-related value creation fits with the processes of the other functional units, such as HR, ICT and operations. For example, a new employee would have an easy and timely access to the needed facilities, services and equipment at her/his arrival; acquired office would meet the ICT needs of a company; and corporate operations (such as R\&D and production) and their employees would not be disturbed by maintenance or renovation projects.

Second, being able to reduce waste in the intra-functional alignment ( 3 in Figure 1) provides synchronisation between the decision areas of CRE in terms of time, content and resources. For example, avoiding cleaning of the windows before a facade renovation; avoiding heavy workplace investments in properties with exit strategy; or avoiding rework, errors and overprocessing due to the lack of internal communication. Similarly, waste reduction in cross-functional alignment provides the same benefits but across the value chain. For example, creating a flow in the value chain would reduce waiting from the user perspective, would level the workload of the employees in the value chain and would offer higher quality service delivery.

Lean aligns especially horizontally and, thus, it offers a way for smart CREM alignment, i.e., a smart use of CRE resources including not only the use of materials and energy but also the use of human resources with their social capital. To account for waste in horizontal CREM alignment would expand the research from strategic CREM alignment into smart CREM alignment.

The analysis encourages to further study the horizontal CREM alignment within and across organisations. The resource-based CREM research would be thriven by smart use of CRE resources and operational excellence. The CREM theories and practice could also learn from other disciplines such as lean construction and lean health care.

The reconceptualisation of the CREM alignment provides a new way of thinking for academics and practitioners. It offers a resource-smartness approach to manage the secondlargest assets of organisations. The CREM theories, which are still relatively young and nascent, would also benefit by using theories from more mature fields, such as lean supply chain management, process re-engineering and process redesign, outside the strategic management literature. 


\section{REFERENCES}

Alagaraja, M., Rose, K., Shuck, B., and Bergman, M. (2015) Unpacking Organisational Alignment: The View from Theory and Practice, Journal of Organizational Learning and Leadership, 13(1), 19-32.

Appel-Meulenbroek, R.., Brown, M. G., and Ramakers, Y. (2010). "Strategic alignment of corporate real estate", in: Proceedings of the 17th European Real Estate Society (ERES) Conference, 23-26 June 2010, Milan, Italy.

Benner, M.J. and Tushman, M.L. (2003). "Exploitation, Exploration and Process Management: The productivity Dilemma Revisited." The Academy of Management Review, 28(2), 238-256.

Bølviken, T., Rooke, J., and Koskela, L. (2014). "The Wastes of Production in Construction - a TFV Based Taxonomy." In: Proc. 22nd Annual Conference of the International Group for Lean Construction (IGLC), Oslo, Norway, pp. 811-822.

Cooper, M. and Ellram, L. (1993). "Characteristics of Supply Chain Management and the Implications for Purchasing and Logistics Strategy." The International Journal of Logistics Management, 4(2), 13-24.

CoreNet Global (2016) The Essential Guide for Corporate Real Estate. CoreNet Global Inc: Atlanta.

Dewulf, G., Krumm, P., and De Jonge, H. (2000). Successful Corporate Real Estate Strategies. Arko Publishers, Nieuwegein.

Edwards, V., and. Ellison, L. (2004). Corporate property management: aligning real estate and business strategy. Blackwell Science: Malden.

Den Heijer, A.C. (2011) "Managing the university campus: Information to support real estate decisions." Doctoral Diss., Faculty or Architecture, Delft University of Technology.

Harris, R. and Cooke, H. (2014). "Is corporate real estate at a crossroads?" Journal of Corporate Real Estate, 16(4), 275-289.

Henderson, J., and Venkatraman, H. (1989). Strategic alignment: A framework for strategic information technology management. CISR WO No. 190, Center for Information Systems Research, Sloan School of Management, Massachusetts Institute of Technology.

Henderson, J., and Venkatraman, H. (1993). "Strategic alignment: Leveraging information technology for transforming organizations." IBM Systems Journal, 32(1), 472-484.

Heywood, C., and Arkesteijn, M. (2017) "Alignment and theory in Corporate Real Estate alignment models." International Journal of Strategic Property Management, 21(2), 144-158.

Heywood, C., and Kenley, R. (2010) "An Integrated Consumption-Based Demand and Supply Framework for Corporate Real Estate." In: Proceedings of 2010 International Conference of Construction and Real Estate Management, 1-3 Dec 2010, Brisbane, Australia.

Heywood, C., and Kenley, R. (2013) "Corporate real estate management: More than clients' and users procurement." In: Proceedings of 19th CIB Building Congress.

De Jonge, H., Arkesteijn, M. H., Den Heijer, A. C., Vande Putte, H. J. M., De Vries, J. C., and Van der Zwart, J. (2009). Corporate real estate management: designing an 
accommodation strategy. Research report, Faculty of Architecture, Delft University of Technology.

Kathuria, R., Joshi, M., and Porth, S. (2007). "Organizational alignment and performance: Past, present and future." Management Decisions, 45(3), 503-517.

Krumm, P.J.M.M., Dewulf, G. and De Jonge, H. (1998). "Managing key resources and capabilities: pinpointing the added value of corporate real estate management", Facilities, 16(12/13), 372-379.

Krumm, P.J.M.M., and De Vries, J. (2003). "Value creation through the management of corporate real estate." Journal of Property Investment \& Finance, 21(1), 61-72.

Lehtonen, T. and Salonen, A. (2006). "An empirical investigation of procurement trends and partnership management in FM services - A Finnish survey." International Journal of Strategic Property Management, 10(2), 65-78.

Leväinen, K.I. (2013) Kiinteistö- ja toimitilajohtaminen. Gaudeamus: Helsinki.

Lindholm, A.-L., and Leväinen, K.I. (2006). "A framework for identifying and measuring value added by corporate real estate." Journal of Corporate Real Estate, 8(1), 38-46.

Lindholm, A.-L., and Nenonen, S. (2006). "A conceptual framework of CREM performance measurement tools." Journal of Corporate Real Estate, 8(3), 108-119.

Lindholm, A.-L. (2008) "Identifying and Measuring the Success of Corporate Real Estate Management." Doctoral Diss, Department of Surveying, Helsinki University of Technology.

Jensen, P.A. (2008). "The origin and constitution of facilities management as an integrated corporate function." Facilities, 26(13/14), 490-500.

Jensen, P. A., Van der Voordt, T. J. M., Coenen, C., von Felten, D., Lindholm, A.-L., Nielsen, S. B., Riratanaphong, C., and Pfenninger, M. (2012). "In search for the added value of FM: what we know and what we need to learn." Facilities, 30(5/6), 199-217.

Jensen P.A. and Van der Voordt, T. (2017) Facilities Management and Corporate Real Estate Management as Value Drivers - How to manage and measure adding value. Routledge, New York, NY.

Jylhä, T. (2013). "Creating Value or Waste? Evaluating the Production of Real Estate Services with Lean Thinking." Doctoral Diss., Aalto University publication series Doctoral Dissertations, 148/2013.

Jylhä, T., and Junnila, S. (2014). "The State of Value Creation in the Real Estate Sector Lessons from Lean Thinking." Property Management, 32(1), 28-47.

Jylhä, T., Remøy, H., and Arkesteijn, M. (2019) "Identification of changed paradigms in CRE research - A systematic literature review 2005-2015." Journal of Corporate Real Estate, 21(1).

Lee, R.G., and Dale, B.G. (1998). "Business process management: a review and evaluation." Business Process Management Journal, 4(3), 214-225.

McCarty, T. D., and Gottschalk, D. (2014). "Capabilities of the new strategic organization." Journal of Corporate Real Estate, 16(4), 290-300.

Nourse, H. O., and Roulac, S. E. (1993). "Linking real estate decisions to corporate strategy." Journal of Real Estate Research, 8(4), 475-495. 
Riratanaphong, C. (2014). "Performance measurement of workplace change in two different cultural contexts." Doctoral Diss., Faculty of Architecture and the Built Environment, Delft University of Technology.

Roulac, S. E. (2001). "Corporate property strategy is integral to corporate business strategy." Journal of Real Estate Research, 22(1/2), 129-151.

Schniederjans, M.J., Schniederjans, D.G. and Schniederjans A.M. (2010). Topics in Lean Supply Chain Management., World Scientific Publishing, Mainland Press, Singapore.

Sharma, A., Saxena, A., Sethi, M., Shree, V., and Varun (2011). "Life cycle assessment of buildings: A review." Renewable and Sustainable Energy Reviews, 15(1), 871-875.

Sharp, D. (2013). "Risks ahead: the transformation of the corporate real estate function." Journal of Corporate Real Estate, 15(3/4), 231-243.

Skinner, W. (1974) The Focused Factory, Harvard Business Review, 52, 113-121.

Then, D. S. S. (2005). "A proactive property management model that integrates real estate provision and facilities services management." International Journal of Strategic Property Management, 9(1), 33-42.

Then, D. S. S., Tan, T. H., Fonseca Santovito, R., and Jensen, P. A. (2014). "Attributes of alignment of real estate and facilities management to business needs." Journal of Corporate Real Estate, 16(2), 80-96.

Then, D. S. S., and Tan, T. H. (2013). Facilities management and the business of managing assets. Abingdon: Routledge.

Torraco, R. (2005). "Writing Integrative Literature Reviews: Guidelines and Examples." Human Resource Development Review, 4(3), 356-367.

Trevor, J., and Varcoe, B. (2017). "How aligned is your organisation?" Harvard Business Review, February 2017.

Van der Voordt, T. (2016). "The Delft legacy of Adding Value by CREM." in Arkesteijn, M. (Ed.), Van der Voordt, T. (Ed.), Remøy, H. (Ed.), Chen, Y. (Ed.), \& Curvelo Magdaniel, F. (2016). Dear is Durable: Liber amicorum for Hans de Jonge, Delft University of Technology.

Vrijhoef, R., and Koskela, L. (2000). "The four roles of supply chain management in construction." European Journal of Purchasing and Supply Management, 6(3-4), 169178.

Weatherhead, M. (1997). Real estate in corporate strategy. Houndmills, Macmillan Press.

Wheelwright, S., and Hayes, R. (1985). "Competing Through Manufacturing." Harvard Business Review, 63(1), 99-109.

Yuan Hung, R. Y., Yang, B., Ya-Hui Lien, B., McLean, G.N., and Kuo, Y.-M. (2010) "Dynamic capability: Impact of process alignment and organisational learning culture performance." Journal of World Business,45(3),285-294. 